\title{
Fresh Fruit Time based on STP analysis and statistics method (Changchun) Word-of-mouth marketing strategy research
}

\author{
Yingjie Liu ${ }^{1, a}$, Hongzhong Shan ${ }^{2, b}$ \\ ${ }^{1}$ School of business, Beijing Institute Of Fashion Technology Beijing, China \\ ${ }^{2}$ School of business, Beijing Institute Of Fashion Technology Beijing, China
}

\begin{abstract}
At this stage, the beverage market has become the Red Sea. HEYTEA, Naixue's Tea at the top, and Michelle Ice City, which occupies third- and fourth-tier cities, account for most of the total market. How to gain a competitive advantage in the beverage market where competition is fierce and marketing methods tend to be consistent is a problem that Fresh Fruit Time (Changchun) needs to solve. This paper analyzes the existing marketing mix of Fresh Fruit Time (Changchun) and finds that it has shortcomings in word-of-mouth marketing. With the help of STP analysis and statistics method, combined with Fresh Fruit Time's product characteristics and business philosophy, it identifies young white- collar women as the target market, positioning a healthy and comfortable buying environment, and proposing word-of-mouth marketing suggestions for creating topical events through related media, viral communication and search marketing optimization. The combination of STP and statistics method is an innovation, making statistical methods more realistic.
\end{abstract}

\section{OVERVIEW OF Fresh FruIt TIME ENTERPRISE}

\subsection{Development status}

Time fruit company is headquartered in Beijing, was established in 2007 years 4 months, the second year in March, Fresh Fruit Time to start promoting cooperative shares Direct store model, relatively less investment, low risk, high return, return fast emerging areas, cooperation stores opened in full swing, as of 2019 Nian number of stores Chaoguo 1000 home. Fresh Fruit Time's main products include juices, tea drinks, and milk beverages. It always adheres to the business tenet of freshness and health, and uses fresh, high-quality raw materials to satisfy consumers' pursuit of quality.

\subsection{Deficiencies in word-of-mouth marketing}

The direction of dissemination of Fresh Fruit Time product information is still focused on the targeted dissemination of enterprises to consumers. In the virtual online community, brand mention rate and topic discussion are low, and consumers often need to spend relatively more cost to obtain product information. The same type of fashion beverage outlets like HEYTEA and A little by new media such as microblogging, vibrato and other carrier body, through the spread of the virus in a short time, quickly open the well-known across the country, and continue to maintain a buzz, by creating a network Explosive products attract young consumers, making them a fashion label and traffic brand.

\section{STP ANALYSIS OF WORD-OF-MOUTH COMMUNICATION}

\subsection{Market Segmentation}

There are two main types of beverages on the market, one type contains alcohol in the ingredients, and the other type contains no alcohol in the ingredients. The category of non- alcoholic drinks includes fruit and vegetable drinks, bottled water drinks, protein drinks, coffee drinks, tea drinks, dairy products, and functional drinks.

In 2018, China's beverage retail sales reached 204 billion yuan, a year-on-year increase of 9\%. From January to December 2019, China's beverage retail sales exceeded 200 billion yuan, reaching 209.9 billion yuan, a cumulative increase of $10.4 \%$. According to Beverage Industry 2019 Statistical data show that the share of the market tea amount of about $21.12 \%$.

Currently, tea is one of the main types of drinks on the market, 2018, China's tea drink market broke out, as of 2018Q3 National freshly made tea shop number has reached 41 thousand, 2019 year-end, tea drinks in the beverage market share of about $20 \%$, the annual output is nearly 10 million tons.

In terms of gender preference, men and women have basically the same preference for bottled water and tea beverages, both of which belong to the most popular beverage categories. Men prefer carbonated and functional drinks, while women prefer fruit and vegetable

\footnotetext{
* Corresponding author: aliuyingjie1111@163.com, ${ }^{\mathrm{b}}$ shz0306@sina.com
} 
and dairy drinks, as shown in Figure 1.

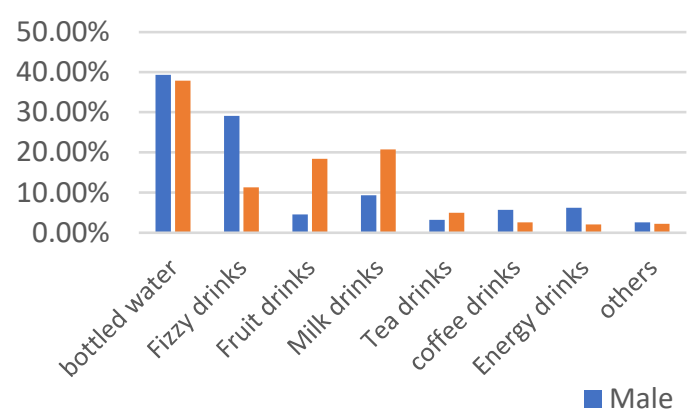

Figure 1. Drink gender preference graph

At the same time, women are more likely than men to be affected by external factors, such as friend recommendations, advertisements and other factors to try new brands or products, while men's brand loyalty is significantly higher than women's. After investigating the beverage preferences of different income groups, it is found that low-income groups prefer carbonated beverages, and high-income consumers have a higher demand for coffee beverages. There is little difference between different income consumer groups for tea beverages, fruit juices, and vegetable beverages, as shown in Figure 2.

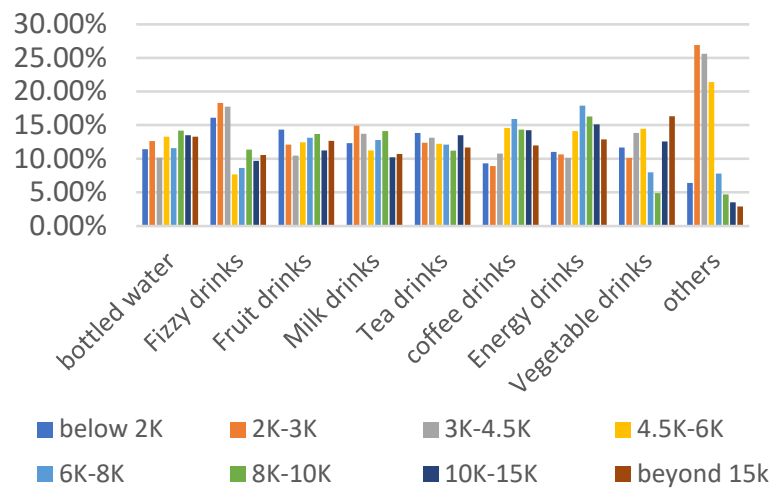

Figure 2. Beverage preference chart of different income levels

\subsection{Target market}

\subsubsection{Analysis of category preference}

According to survey data, the proportion of consumers buying fruits and vegetables and tea drinks is $54.46 \%$ and $47.52 \%$, ranking the top two. The proportion of consumers who buy lactic acid bacteria and bottled drinking water is roughly the same, indicating that consumers' preference for them is roughly the same, but lower than that of fruits and vegetables and tea drinks. The number of consumers who choose carbonated drinks is the least, accounting for $9.9 \%$. Buy fruit and vegetable drinks consumer survey results showed that $75 \%$ of consumers in the purchase, it will focus on its fruit and vegetable content with $66 \%$ of consumers will buy fresh squeezed fruit and vegetable drinks, and that fresh juice drinks, its nutritional content Higher and healthier. This shows that consumers who buy fruit and vegetable beverages have the main consumer psychology to pursue health. This part of consumers has a high degree of acceptance of the prices of fruit and vegetable drinks.

\subsubsection{Gender differences in beverage consumption and age distribution of female consumers}

In terms of gender, female consumers accounted for $78 \%$ of beverage purchases and $22 \%$ of male consumers. And women consume more fresh milk and juice drinks, while men buy more functional drinks. In the female buyers, the 25 -year-old -30 -year-old age group accounted for the vast majority of consumers, is $73 \%$. The other age groups account for relatively small proportions.

\subsubsection{Consumer psychology and consumption characteristics of white-collar women}

\subsubsection{Emphasis on appearance and image, and strong desire for beauty}

According to statistics, when female consumers buy products, the first thing they pay attention to is the appearance, color, style, and packaging of the product, while practicality and price are the last considerations. In the purchase decision process, irrational factors play a stronger role.

\subsubsection{2 irrational consumption, love thread consumption}

In 2019, Horizon Research Company's "Study on the Consumption Aspects of Urban Young Women" investigated the irrational consumer behavior of women in major cities in China from the perspectives of values and consumption outlook. The survey results show that $94 \%$ of women have irrational consumption behaviors, and irrational consumption accounts for $20.0 \%$ of female consumption expenditures.

\subsubsection{The super influence of word-of-mouth communication}

Word-of-mouth communication is an important source of information that affects the consumption of white-collar women. White-collar women have a higher education level, have a strong cognition of existing marketing methods, and maintain a high level of vigilance towards business promotions. Therefore, they prefer to get relevant information from friends or friends of friends. Product-related information and believe that its credibility is higher.

\subsubsection{Be picky about details}

Compared with men, women pay more attention to the details of things when shopping. 


\subsubsection{5 sensitive to price}

Among the messages transmitted between women, the amount of information about brand discounts often accounts for the majority.

\subsubsection{Attach importance to pursuing fashion, enjoying life, and treating yourself well}

With the increase in the number of women in the workplace, as well as the improvement of their own cultural level, and the increase in economic independence, they are more pursuing themselves, pursuing a high-quality life, and enjoying life while actively working.

\subsubsection{Focus on a full range of consumer experience}

In the shopping environment, women have higher requirements. They usually prefer to visit large-scale shopping malls with convenient transportation, good supporting facilities, comfortable shopping environment, food, leisure and entertainment.

Therefore, the target market as 18-28 year-old young female white-collar small capital.

\subsection{Market Positioning}

The main target consumers of "A little" are middle school students, and the outlets are mostly distributed around the school. Its market positioning is "deeply customized drinks", and consumers can choose "less ice, sweetness, what to add" according to their preferences when ordering meals.

"COCO Tea Drinks" is mainly positioned as "tea drinks", and product development is mainly based on "tea drinks". Stores are mainly located at the entrance of campus, near the station, and large markets.

Other self-employed individuals are mainly scattered in commercial streets such as Guilin Road due to factors such as scale, brand influence, and capital.

From the two dimensions of product taste preference and shopping environment comfort, the market positioning of the main competitors in the existing market is analyzed, and it is found that there are market gaps in areas where beverage tastes are weak and shopping environment comfort is relatively high. Moreover, the main target consumers of Fresh Fruit Time are young white-collar workers who pursue health, so they prefer lighter-tasting drinks and pursue a full range of consumer experience. Therefore, it is necessary to provide a highly comfortable shopping environment, as shown in Figure 3. Therefore, the market positioning of Fresh Fruit Time is fresh, healthy and fashionable.

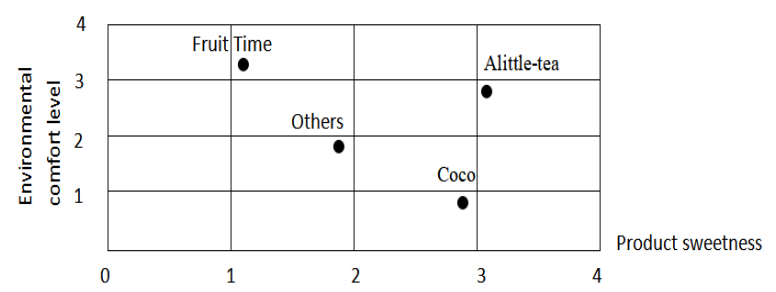

Figure 3. Competitor market positioning

\section{WORD OF MOUTH MARKETING STRATEGY}

\subsection{Media Choice}

\subsubsection{Tik Tok}

Tik Tok's target audience is young people. Tik Tok's content, interaction methods, and communication methods are consistent with the characteristics of young people who are willing to express themselves, pursue trends, and are willing to socialize.

There are four forms of advertisement delivery methods: open screen advertisement; information flow advertisement; sticker advertisement; Fruit Time makes video advertisement. The video is inserted between the short videos viewed by the user. The length of the video advertisement is 15 seconds. The secondary dissemination on other platforms achieves the effect of expanding influence and continuous dissemination.

\subsubsection{Video Platform's Reality Show}

In recent years, self-made variety shows such as "China's hip hop" and "creation 101" and other emerging reality TV shows have enjoyed high ratings. The target market of these variety shows is the minority youth subculture, and is warmly welcomed by the youth groups pursuing individuality. High ratings mean the increase of brand exposure of sponsors. There is a high degree of overlap between the target market of Fruit Time and the main audience of this kind of shows. With the help of this type of variety show sponsorship, we can establish and strengthen the brand position in the hearts of consumers.

The advertising mode of online includes simple exposure of brand logo, in-depth embedding of variety show content.

\subsection{Search optimization}

\subsubsection{Edit Baidu Encyclopedia}

The company profile, development history, corporate culture, product characteristics and related news of Fruit Time will be integrated, edited, uploaded and displayed firstly, which is located above the Business advertisement of Fruit Time. It is convenient for consumers to know the relevant information of Fruit Time. 


\subsubsection{Optimize Takeaway Platform Reviews}

According to the survey data, $33.96 \%$ of the customers read the comments and refer to them every time when shopping, and $49.06 \%$ of the customers often read and refer to them. The most commonly used takeaway software for consumers are Meituan and ELEME, and the most preferred comment form of consumers is the form of pictures, followed by pure text font, and finally the form of video.

Fruit Time should encourage consumers to comment on the takeaway software after purchasing Fruit Time products. For the negative comments, the company should make timely and targeted reply from the after-sales department to solve the problems existing in the process of purchasing products, and timely record, sort out and feed back to the management of the company. For the constructive and objective problems raised by consumers, the company will give a certain degree of reward, and publicize the award-winning consumers in places easy to be seen by consumers, such as the comment top area and the store public screen.

\section{CONCLUSION}

When the competitive landscape of the beverage market is basically formed, how to make consumers repeat purchases is a problem that companies need to solve. From the perspective of word-of-mouth marketing under the marketing strategy, this article analyzes the shortcomings of Fresh Fruit Time in word-of-mouth marketing, and uses STP analysis to clarify its market positioning, which provides a reference for the implementation of a differentiated strategy. Combining existing communication channels, provide suggestions from two aspects of media selection and word-of-mouth marketing methods.

\section{REFERENCES}

1. Amdt.J. Role of Product related Conversations in the Diffusion of a New Product. Journal of Marketing Resarch ,4, 2015, pp.291 - 295.

2. Soderlund, Magnus. Customer Satisfaction and Its Consequences on Customer Behavior Revisited. International Journal of Service Industry Management. 9(2). 2018, pp.169 188.

3. Godes, David, Dina Mayzlin. Using Online Conversations to Study Word-of-Mouth Communication Marketing Science. 2016. 23(4)

4. Neveen F.Awad \& Arik Ragowsky. Establishing Trust in Electronic Commerce Through Online Word of Mouth: An Examination Across Genders [J]. Journal of Management Information Systems, 2017(24): 101-121

5. Zuo Wenming, Wang Xu, Fan Xi. The relationship between online word-of-mouth and purchase intention based on social capital in the socialized e-commerce environment [J]. Nankai Management Review, 2014, 17(04): 140-150+160.

6. Wang Changzheng, He Sama, Wang Kui. Research on the usefulness perception of additional comments in Internet word-of-mouth [J]. Management Science, 2015, 28(03): 